\title{
VII
}

\section{GONOCOCCAL OPHTHALMIA}

\author{
By A. E. W. McLACHLAN, M.B., D.P.H., and \\ G. M. THOMSON, M.B., D.P.H.
}

THE importance of the early diagnosis and prompt institution of treatment in the prevention of corneal damage in ophthalmia neonatorum is well recognised. Purulent gonococcal eye infections resulting at some later period of life from inoculation from genito-urinary foci or from some unknown source present at least equal, if not even greater, dangers to sight. The relative infrequency of occurrence of the latter group, and, in the absence of an admitted genital infection, failure to consider the possibility of a gonococcal ætiology may, however, lead to delay in the recognition of the true cause with consequent risk of visual impairment. The occurrence since I936 of 6 cases of purulent gonococcal ophthalmia - in three instances before recognition of the associated genital infection, and in three instances sporadic, i.e., without concomitant genital infectionresulting in the complete loss of sight of one eye in each of 2 cases and a slightly marked nebula in a third, emphasises the seriousness of this condition.

\section{Cases Associated With but OCcurring Before Diagnosis of Genital GonorrheEA}

(I) Tf. 4042. Female, aged I8 years. Single. Reported March I2th, I936.

For one month had noticed slight inconstant irritation of left eye (? toxic conjunctivitis from genital gonorrhœa). Five days previously the irritation of the eye became more marked and a slight serous discharge was noticed; forty-eight hours later marked pain and sero-purulent discharge, gradually becoming worse. On admission : marked photophobia, profuse purulent discharge, œdema of upper and lower eyelids, slight chemosis, cornea clear. Right eye unaffected. Smears showed the presence of pus and gonococci in conjunctival secretion. Progress 
under treatment satisfactory. Patient discharged on May I5th, I936, no corneal damage. The genito-urinary infection cleared up without complications under routine treatment. W.R. found to be ++ , and patient still under observation for syphilis.

(2) Tf. 5537. Female, aged 43 years. Reported December 21st, I936.

Eight days previously had noticed irritation of left eye with slight photophobia; twenty-four hours later slight discharge gradually becoming worse. On the fourth day, because of severe pain and discharge, she

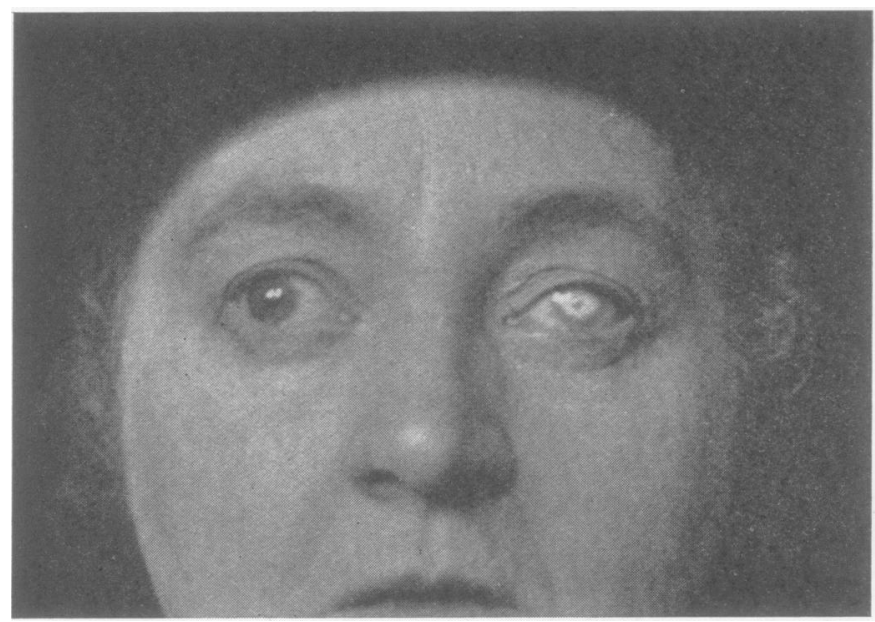

FIG. I.-End result of Case 2-dense corneal leucoma and complete loss of vision of left eye.

consulted a doctor who advised her to report to hospital and prescribed an eye-wash. The eye improved slightly with treatment, but after twenty-four hours again became worse and patient finally reported to hospital. On admission : profuse purulent discharge, marked œdema of both eyelids, the upper overhanging the lower, cornea cloudy and slight chemosis. Smears, Pus, $++\mathrm{Gc}++$ in conjunctival secretion. Subsequent progress : despite treatment, a central perforation of the cornea occurred and patient was finally discharged on February 27th, I937, with a dense leucoma almost completely covering the corneå. Course of concomitant gonorrhœa uneventful (Fig. I).

(3) M. I552. Male, aged 38 years. Reported October 26th, I938. 
Six days previously had noticed irritation of right eye; discharge commenced forty-eight hours later, gradually becoming purulent; slight pain and photophobia. On examination profuse purulent discharge from right eye, marked œdema of both lids, the upper overhanging the lower; marked fleshy chemosis. Cornea presented a slightly ground glass appearance. Smears, Pus $+\mathrm{Gc}+$. W.R. negative, Gc F.T. negative. Under routine local treatment plus M. \& B. 693 the condition rapidly subsided, the eye being pus-free in three days and the œdema of the lids almost completely resolved. The fleshy chemosis, however, persisted, and had not completely resolved until the middle of the third week ; patient was discharged from hospital on November 26th, I938. End result: superficial nebula, slightly hollowed out, in upper part of cornea. Some small peripheral nebulæ at the outer limbus on the level of the main nebula. No sign of any involvement of the deeper layers of the cornea. No traces of any corneal nebula in lower corneal hemicircle. The genital gonorrhœa was completely cleared up by the M. \& B. 693 administration without local treatment.

Cases $I$ and 2 admitted the presence of a vaginal discharge for some indefinite time before the occurrence of the eye infection, but had disregarded it as the symptoms were slight. Case 3 had noted a slight symptomless urethral discharge for ten days before the commencement of the purulent conjunctivitis.

\section{Sporadic Cases, i.e., without Concomitant Genital InFECTION}

(4) T. 7454. Male, aged 26 years. Single. Reported October 2Ist, I937.

Three days previously had felt irritation of both eyes ; one day later noted discharge at first serous, but rapidly becoming purulent. On examination, purulent discharge from both eyes, slight œdema of lids, no chemosis, cornea clear. Smears, Pus, ++ in both eyes, Gc + in right eye, not demonstrated in left eye. W.R. negative, Gc F.T. negative. Under treatment the condition cleared up rapidly, and patient was discharged from hospital on November 9th, 1937, with no corneal damage. Source of infection ascribed to dirty lavatory towel. 
(5) Tf. 7820. Female, aged 3 years. Reported December 3rd, I937.

Eight days previously " right eye started to ooze pus "- treated with boric baths and fomentations. Six days later marked swelling of the right eyelids occurred, the left eye was discharging; medical advice was then sought. On examination, profuse purulent, slightly hæmorrhagic discharge from right eye, marked odema of eyelids-upper overhanging the lower ; cornea slightly

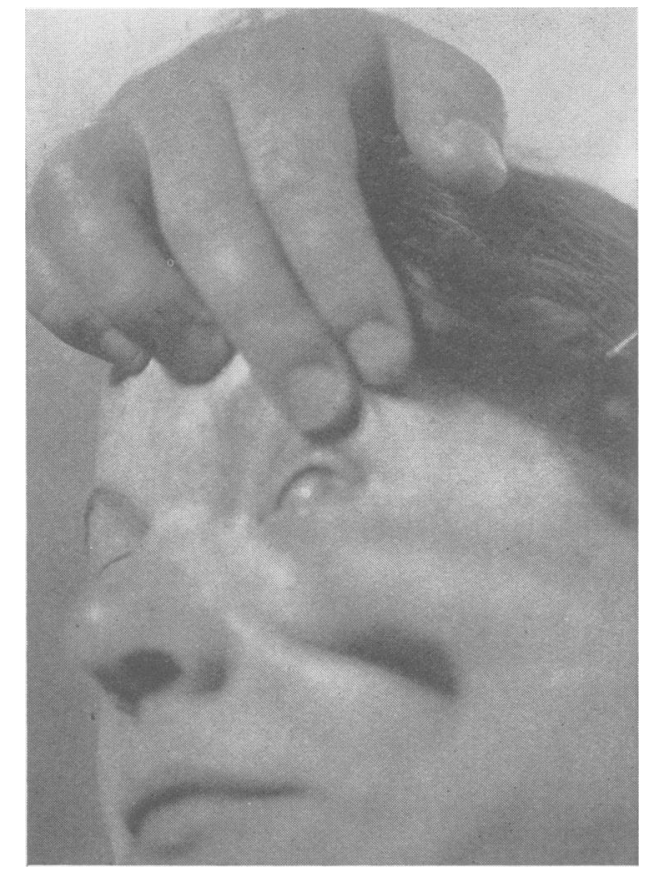

FIG. 2.-End result of Case 6-leucoma and anterior staphyloma: complete loss of vision of left eye.

opaque. Discharge and odema less marked on left side, cornea clear. Smears, Pus ++ and $\mathrm{Gc}+$ in smears from both eyes. Blood, W.R. negative, Gc F.T. negative. Under treatment the condition improved rapidly, and after eighteen days both eyes were practically pus-free. Discharged on thirty-second day after fourteen days observation. No corneal damage. No source of infection ascertained.

(6) A. I Io. Female, aged 27 years. Single. Reported February IIth, I938. 


\section{GONOCOCCAL OPHTHALMIA}

Five days previously noticed redness and slight discharge of right eye, which rapidly became worse; three days later, swelling of eyelids. On examination, purulent discharge from left eye, marked œdema of upper lid which overhung lower. Slight chemosis. Cornea opaque. Smears, Pus $++\mathrm{Gc}++$. Blood, W.R. negative. Gc F.T. negative. Right eye unaffected. Twenty-four hours after admission, central perforation of the cornea occurred. The subsequent course of the disease was protracted, the patient being discharged on the ninety-eighth day with a dense corneal opacity and an anterior staphyloma. Sulphanilamide was exhibited, but was discontinued after the second dose because of severe vomiting. This patient ascribed the infection to a towel used in a railway toilet two days before the onset of the symptoms (Fig. 2).

\section{INCIDENCE}

The incidence of purulent gonococcal conjunctivitis, in view of the accidental nature of the contagion, is difficult to assess. Table I, however, shows the local incidence and end results since I936:

\section{TABLE I}

\begin{tabular}{|c|c|c|c|c|c|c|c|}
\hline \multirow{3}{*}{ Year } & \multirow{2}{*}{\multicolumn{2}{|c|}{$\begin{array}{l}\text { Total Number of } \\
\text { Cases of Gonorrhœea } \\
\text { under Treatment }\end{array}$}} & \multicolumn{4}{|c|}{ Gonococcal Ophthalmia } & \multirow{3}{*}{$\begin{array}{c}\text { End Result of Affected } \\
\text { Eye(s) }\end{array}$} \\
\hline & & & \multicolumn{2}{|c|}{$\begin{array}{l}\text { Associated with } \\
\text { Genito-urinary } \\
\text { Infection }\end{array}$} & \multicolumn{2}{|c|}{ "Sporadic" } & \\
\hline & Male & Female & Male & Female & Male & Female & \\
\hline 1936 & 1,304 & 293 & - & 2 & - & - & $\begin{array}{l}\text { One eye infected in } \\
\text { each case. Recovery } \\
\text { in one, loss of sight } \\
\text { in one. }\end{array}$ \\
\hline I 937 & 1,367 & 257 & - & - & I & I & $\begin{array}{l}\text { Both eyes infected in } \\
\text { male-recovery com- } \\
\text { plete. Bilateral in- } \\
\text { fection in female- } \\
\text { recovery complete. }\end{array}$ \\
\hline $193^{8}$ & 1,423 & $25^{6}$ & I & - & - & I & $\begin{array}{l}\text { Unilateral infection } \\
\text { in male - slight } \\
\text { superficial nebulæ } \\
\text { over upper portion } \\
\text { of cornea. Uni- } \\
\text { lateral infection in } \\
\text { female - complete } \\
\text { loss of vision. }\end{array}$ \\
\hline
\end{tabular}




\section{Clinical Course}

The clinical course is similar to, but frequently more rapid and severe than that of ophthalmia neonatorum. Commencing with irritation, slight photophobia, conjunctival injection and scanty serous discharge, the condition rapidly progresses to the characteristic picture of severe pain, marked photophobia, profuse purulent discharge, œdema of the eyelids, the upper one often overhanging the lower and fleshy chemosis.

When chemosis is marked the swollen conjunctiva may overlap the corneal margin leading to retention of pus with consequent risk of marginal ulceration. Corneal clouding, ulceration and perforation may occur with the attendant sequelæ of macula, nebula, leucoma or staphyloma formation, or panophthalmitis.

Normally the line of closure of the eyelids falls opposite the junction of the middle and lower thirds of the cornea. Edema of the lower lid, as may be shown by experimental infiltration in the cadaver, may raise the level of the tarsal border of the lower lid to above the level of the centre of the cornea and may also cause slight inversion of this border, while conjunctival œdema tends to limit the normal upward rotation of the eyeball.

The risk of pressure damage from the comparatively rigid tarsal edge is increased by the pressure from the upper lid, while the upward drag of this lid may increase the inversion of the lower. This sequence is illustrated by the occurrence in Case 3 of superficial nebulæ above the level of the centre of the cornea. In the two cases in which perforation occurred this took place at the centre of the cornea-the area of least nutrition. It seems possible that pressure from the tarsal edge of the lower eyelid may be an important factor in corneal damage. The minimal scarring of the cornea in Case 3 appears to be due to the rapid control of the infection by $M$. \& B. 693. Pre-auricular adenitis with marked pain developed in Case 6 , but no other complications such as abscess of the eyelid, infection of the ethmoid air cells, lachrymal duct, orbital cellular tissue or meninges were seen.

\section{Diagnosis}

In the early stages there is slight photophobia, conjunctival injection and a scanty serous discharge as in 218 


\section{GONOCOCCAL OPHTHALMIA}

other bacterial infections. In toxic conjunctivitis discharge and odema are slight and chemosis is absent. A later accidental contagion superimposed on a toxic conjunctivitis may have occurred in Case I. The importance of microscopical examination of smears of the exudate in early cases is emphasised : in the majority the gonococcus is easily demonstrated. In advanced cases the clinical picture gives rise to little doubt as to the probability of gonococcal infection.

\section{PROGNOSIS}

In general the earlier the diagnosis is made the more favourable the outcome. Any suggestion of corneal opacity or ulceration is of serious import as to the preservation of vision. Since the utmost care should be taken to prevent corneal damage during irrigation or instillation a skilled attendant is essential. Ulceration invariably follows injury and pressure on the eyeball in separating the lids may cause rupture of the floor of the ulcer.

\section{Preventive Aspects}

The eye may be infected by digital contamination in a patient suffering from genital gonorrhœa; by direct infection of the clinician or nurse from ophthalmic or genital gonorrhœal infections: or from contaminated towels, sponges or other toilet appliances. Digital infection of the eye is stated to be more common in males than in females and the right eye more frequently affected in right-handed persons than the left. Cases I and 3 support this rule-a left-handed female having a left eye and a right-handed male a right eye involved. In Case 2 , however, a right-handed female, the left eye was involved.

The necessity of impressing on patients affected with genital gonorrhœa how to avoid contaminating the eyes is evidently well recognised and carried out as eye infections in practice are rare. Strict nursing precautions and the provision of goggles for those treating cases of ophthalmia neonatorum are necessary. In 3 cases coming under our notice in which there was a probability of accidental eye infection, immediate prophylaxis of Credé type following lavage proved successful. The avoidance 
of other than freshly laundered towels and the use of strictly personal toilet equipment obviate any risk of sporadic contagion.

\section{TREATMENT}

Immediately on admission to hospital the unaffected eye must be protected with a Buller's shield. The eyes should be kept discharge free by frequent lavage with weak antiseptic solutions such as $\mathrm{I} / 20,000$ Potass. Permang., I/6,ooo Mercurochrome, boric lotion or saline, at first at half-hourly intervals. Later, astringent lotions, such a I/2,000 zinc sulphanilate or zinc sulphocarbolate, are indicated. Atropine drops are applied once daily and instillations of $I / I, 500$ neutral flavine in castor oil or ro to 25 per cent. argyrol are given fourhourly, or more frequently in severe cases. Painting the palpebral conjunctiva with I to 2 per cent. silver nitrate solution is favoured by many, but was not found necessary in this series of cases.

The introduction of sulphonamide compounds for gonorrhœal infections has materially improved the outlook of purulent gonococcal conjunctivitis. In Case 3, and in two recent cases of ophthalmia neonatorum, treated with M. \& B. 693, the results clinically and bacteriologically were dramatic, the eye being pus-free in three days. In view of the possibility of intolerance, as in Case 6, the routine local treatment should be commenced at once.

In the present series of cases vaccines were not employed; these have been proved a valuable adjunct in the treatment of ophthalmia neonatorum. Operative measures were not required in our cases. External canthotomy may have to be considered in cases in which narrowness of the palpebral fissure and œdema of the lids interfere with efficient lavage and especially when chemosis and pus retention threaten marginal ulceration.

\section{Summary AND Conclusions}

Six cases of purulent gonococcal ophthalmia are reported. In 3 cases infection of the eyes occurred before recognition of the associated genital infection: in the remaining 3 cases, without concomitant genital gonorrhœea, the source of infection was not ascertained, but was ascribed in two instances to dirty lavatory towels. 
In each of 4 cases one eye alone was affected; in the remaining two the infection was bilateral.

That a purulent gonococcal conjunctivitis remained unilateral in 4 cases out of 6 , despite the possibilities of contagion of the non-infected eye, is a striking feature and in sharp contradistinction to the commonly bilateral nongonococcal forms of conjunctivitis.

Of the 8 eyes affected, complete loss of vision resulted in two, and a slightly marked nebula in a third.

The seriousness of the condition, the necessity for early bacteriological investigation of any suspicious conjunctivitis, especially if unilateral, and the early institution of treatment are emphasised.

The in-patient care of Cases I and 2 was carried out by Dr. Sydney Thompson to whom we are indebted for the clinical details covering this period: we are also indebted to Mr. Alex MacRae for helpful advice and criticism.

(Since the above was written, a further case has come under our care. M. 270I, male, aged 34 years, righthanded. Reported on May I2th, I939, with genital gonorrhœa. Treated with Albucid orally and permanganate irrigations. Did not return till June IIth, I939, when admitted to hospital with a purulent conjunctivitis of three days' duration. Stated that the urethral discharge had ceased in three days and had considered himself cured despite an intermittent gleet. On examination : purulent discharge from left eye, slight chemosis, no corneal involvement. Pus $++\mathrm{Gc}++$. Right eye clear. Slight muco-purulent urethral discharge, Pus $++\mathrm{Gc}+$. Under routine lavage and M. \& B. 693 the eye condition improved rapidly, and now on the fifth day of treatment is pus-and organism-free. Under observation, and treatment for genital infection.) 